Vol.24, No.2, Desember 2018

ISSN (p): 1693-590x, ISSN (e): 2686-4711

DOI: $10.36309 /$ goi.v24i2.96

\title{
Rancang Bangun Alat Pemilah Sampah Otomatis Berbasis Arduino Mega 2560
}

\author{
Ernes Cahyo Nugroho*1, Anton Respati Pamungkas ${ }^{2}$, Ika Parlina Purbaningtyas ${ }^{3}$ \\ ${ }^{13}$ Program Studi Sistem Komputer; ${ }^{2}$ Program Studi Informasi; \\ ${ }^{123}$ STMIK AUB Surakarta, Indonesia \\ e-mail: *11ernes.cahyo@stmik-aub.ac.id, ${ }^{2}$ anton18@stmik-aub.ac.id, ${ }^{3}$ ika.parlina90@gmail.com
}

\begin{abstract}
Abstrak
Dumpster management system on Village/Warukkalong Village, RT/RW: 05/01, Kecamatan Kwadungan, Ngawi, East Java still conventional, i.e. the place one container of trash and garbage not disposed of according the trash, which affects trash piled up on one container of trash that impact to the declining environmental quality. Automatic trash can is one of the alternatives that can be used to sort out the type of garbage so that waste management more effectively in order to increase comfort and maximum possible waste reduction. Parser tools architecture garbage garbage sorting type aiming for, so that waste can be separated based on the type of waste, whether inorganic or organic waste garbage can be processed. The garbage will be disaggregated automatically by using a Sensor. The sensor used in auto IE trash proximity capacitive to detect an-organic, as well as inductive proximity to detect the types of bins, and Ultrasonic sensors to detect the height of the garbage and LCD to display the condition and type of garbage. The results of testing on the bin automatically is the maximum size that can be entered approximately $5 \mathrm{~cm} \times 10 \mathrm{~cm}$ with a time of 10-17 seconds from the first go in the garbage into the trash until the end.
\end{abstract}

Kata kunci: Trash, Arduino Mega, Proximity Sensor, Inorganic, organic, metallic, Ultrasonic Sensors

\section{PENDAHULUAN}

Peningkatan pada jumlah penduduk dan laju pertumbuhan ekonomi serta pembangunan disuatu daerah selain mempunyai dampak positif juga menimbulkan dampak negatif. Lingkungan yang sehat adalah lingkungan yang bebas dari polusi dan sampah, salah satu faktor yang menyebabkan lingkungan tercemar adalah masalah sistem pengolahan tempat sampah.

Sistem pengelolaan tempat sampah di Kelurahan/Desa Warukkalong, RT/RW: 05/01, Kecamatan Kwadungan, Kabupaten Ngawi, Jawa Timur masih tidak dikelola dengan baik yakni dengan membuang sampah sembarangan tanpa adanya pemilahan terlebih dahulu, umumnya tempat sampah juga masih konvensional, yakni masih menempatkan satu wadah tempat sampah dan sampah tidak dibuang sesuai golongan sampah, yang berdampak sampah menumpuk dan tercampurnya sampah logam, organik, dan anorganik disatu wadah tempat sampah yang memiliki dampak kepada menurunnya kualitas lingkungan.

Adanya keterbatasan dari sistem tempat sampah konvensional, maka salah satu solusinya dengan merancang dan membangun Alat Pemilah Sampah Otomatis Berbasis Arduino Mega 2560. Alat Pemilah Sampah otomatis ini dapat memilah sampah sesuai jenis sampah yang telah ditentukan seperti sampah logam, sampah organik, dan sampah anorganik dengan memanfaatkan teknologi mikrokontroller berbasis Arduino mega dengan kemampuan mendeteksi jenis sampah menggunakan teknologi sensor proximity induktif dan sensor proximity kapasitif.

Received November 12, 2018; Revised November 28, 2018; Accepted December 10, 2018 


\section{METODE PENELITIAN}

\subsection{Analisa Masalah}

Analisa dan perancangan sebuah alat sangatlah penting. Hal ini bertujuan agar alat yang diciptakan dapat bekerja secara optimal sesuai dengan harapan, selain itu untuk mengurangi kesalahan dalam proses perancangan serta untuk bahan pertimbangan apabila terjadi masalah setelah alat tercipta. Analisis dibuat pada alat pemilah sampah otomatis dapat dikendalikan dengan membaca gerakan tangan yang mendekat menggunakan sensor PIR, membuka pintu menggunakan servo, dan terdapat senso proximity yang berada di dalam bak penampung sampah sementara untuk mendeteksi jenis sampah, dan membaca sampah penuh menggunakan sensor ultrasonik.

Dari analisa system diatas maka penulis mempunyai gagasan atau ide untuk merancang dan membangun suatu prototype yang berjudul "Rancang Bangun Alat Pemilah Sampah Otomatis Berbasis Arduino Mega Atmega 2560". Analisa dalam perancangan alat sebagai berikut.

2.2 Analisa Kebutuhan Pembuatan Alat Pemilah Sampah Otomatis

Untuk realisasi prototype alat pemilah sampah otomatis berbasis Arduino Mega Atmega 2560 diperlukan beberapa perangkat keras sebagai komponen elektronik dan non elektronik sebagai berikut :

a. Utama

1.) Arduino Mega

Sebagai papan sirkuit berbasis mikrokontroler Atmega 2560, sebagai mikrokontroler memiliki 52 pin I/O, sehingga memiliki memori lebih besar sebagai system pengolah input dan output.

2.) Sensor PIR

Sensor PIR sebagai sensor inframerah pasif yang hanya merespon energi dari pancaran sinar inframerah pasif yang dimiliki oleh setiap benda yang terdeteksi maka dari itu Sensor PIR KC7783R sebagai alat pendeteksi gerakan atau keberadaan objek dengan jarak

3.) Sensor Proximity Inductive

Sensor proximity inductive digunakan sebagai Detector sampah Logam.

4.) Sensor Proximity Capacitive

Sensor Proximity Capacitive adalah sensor yang bekerja dengan melihat perubahan nilai kapasitansi benda sensor ini dapat mendeteksi semua objek, maka sensor proximity capacitive dipilih sebagai Detector sampah Anorganik.

5.) Sensor Ultrasonik

Sensor Ultrasonik digunakan untuk mendeteksi atau mengukur jarak ketinggian sensor dengan sampah serta sebagai pendeteksi sampah penuh

6.) Micro Servo SG90

Micro Servo type SG90 adalah servo dengan torsi dan kekuatan yang cukup kuat untuk mebuka pintu tempat sampah dan servo type ini juga low noise sehingga digunakan sebagai Pembuka Pintu Smart Trash Bin

7.) Motor Stepper

Motor Stepper sebagai Penggerak Penampung Sampah Sementara karena dengan stepper motor benda bias bergerak ke posisi tertentu dengan presisi dan akurat

8.) LCD (Liquid Crystal Display)

LCD berfungsi untuk menampilkan data baik dalam bentuk karakter, huruf, angka, grafik mapun sebagai keterangan indikator sampah

9.) $\mathrm{PCB}$ 
PCB (Printed Circuit Board) adalah sebuah papan sebagai pendukung rangkaian komponen elektronika yang berada diatasnya, papan PCB memiliki jalur-jalur konduktor yang terbuat dari tembaga, berfungsi untuk menghubungkan Antara satu komponen dengan komponen lainnya.

10.)Kabel

Menggunakan kabel pelangi dan kabel jumper, kabel pelangi umumnya digunakan pada rangkaian yang memerlukan tegangan rendah terutama pada rangkaian sistem digital. Sedangkan Kabel Jumper berfungsi sebagai komponen elektronika sebagai penghubung antara dua titik atau lebih.

b. Pendukung

1.) Buzzer

Buzzer adalah komponen elektronika berfungsi untuk mengubah getaran listrik menjadi getaran suara, maka dari itu buzzer dipilih sebagai indikator dari sampah penuh

2.) LED

LED digunakan sebagai indikator visual alat pemilah sampah

3.) Resistor

Resistor adalah komponen elektronika yang berfungsi sebagai penatur arus listrik/ sebagai hambatan.

2.3 Perancangan Alat

Perancangan merupakan inti dari seluruh pembuatan penelitian ini. untuk memudahkan perancangan dan pembuatan alat, maka dibuat diagram blok dari sistem secara keseluruhan. Berikut adalah diagram blok dari Rancang Bangun Alat Pemilah Sampah Berbasis Arduino Mega Atmega pada gambar 1.

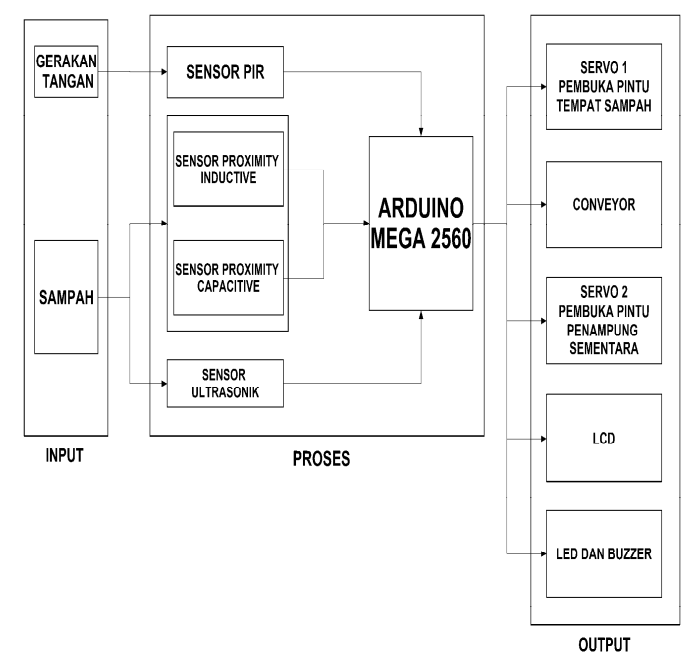

Gambar 1 Diagram Blok Prototype Alat Pemilah Sampah

\subsection{Perancangan Proses}

GO INFOTECH: JURNAL ILMIAH STMIK AUB Vol. 24, No. 2, Desember 2018 : 124 - 133 


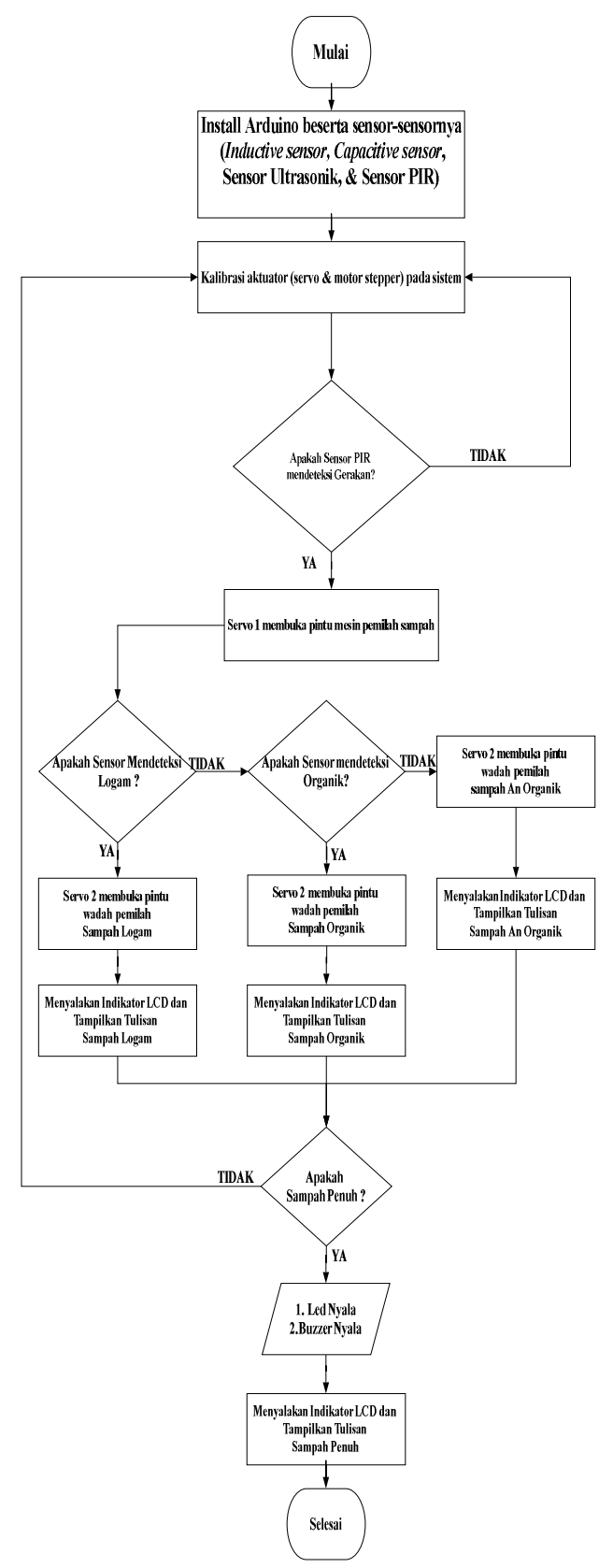

Gambar 2 Diagram Alir Prototype Alat Pemilah Sampah

\section{HASIL DAN PEMBAHASAN}

\subsection{Cara Kerja Alat Pemilah Sampah}

Cara kerja alat pemilah sampah otomatis yakni dari bagian luarnya terlihat pintu tempat sampah yang menggunakan sensor PIR sebagai pendeteksi manusia yang mendekati tempat sampah, kemudian slot pintu akan membuka, setelah itu sampah di masukan ke dalam tempat sampah, lalu sensor akan melakukan proses sensing jika poses sensing berhasil di deteksi conveyor akan berjalan ke bak penampung akhir dengan jenis sampah yang terdeteksi, setelah berhasil LCD akan menampilkan jenis sampah yang terdeteksi, dan tiga buah LED sebagai 
indikator tempat sampah penuh akan berfungsi jika menerima inputan dari maksimal jarak sampah.

a. Pengujian

1.) Pengujian Sensor PIR dan Servo Pintu Tempat Sampah

Pengujian Sensor PIR dilakukan untuk menguji fungsi sensor alat tersebut, dengan mendeteksi suhu tubuh manusia, ketika manusia mendekati alat pemilah sampah otomatis, setelah itu akan menghasilkan output yang akan diproses oleh servo dan servo akan bergerak 40 derajat keatas untuk membuka pintu tempat sampah otomatis yang dapat dilihat pada gambar 3 .

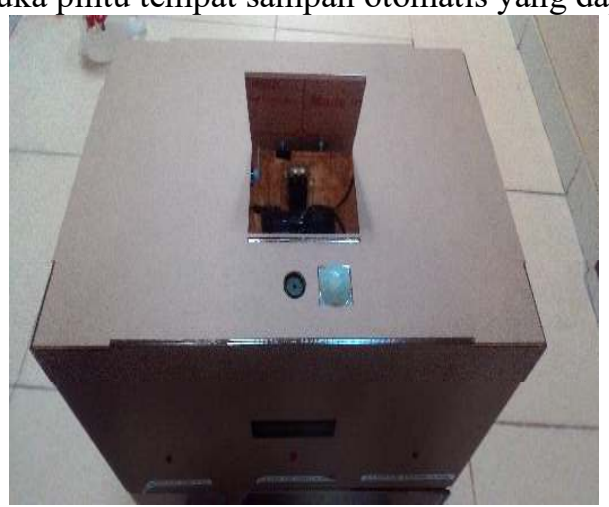

Gambar 3 Pengujian Sensor PIR dan Servo Pintu Tempat Sampah

Hasil dari pengujian sensor PIR sebagai sensor pendeteksi gerakan tangan atau objek mendekati di sekeliling tempat sampah yang telah dilakukan, didapatkan nilai seperti tertera pada tabel 1 .

Tabel 1 Pengujian Sensor PIR

\begin{tabular}{|c|c|c|c|}
\hline Percobaan Ke & $\begin{array}{c}\text { Jarak sensor PIR dengan } \\
\text { manusia }\end{array}$ & $\begin{array}{c}\text { Pengukuran dengan } \\
\text { sensor PIR }\end{array}$ & Keterangan \\
\hline 1 & $5 \mathrm{~cm}$ & $\mathrm{v}$ & Berhasil \\
\hline 2 & $35 \mathrm{~cm}$ & $\mathrm{v}$ & Berhasil \\
\hline 3 & $55 \mathrm{~cm}$ & $\mathrm{v}$ & Berhasil \\
\hline 4 & $75 \mathrm{~cm}$ & $\mathrm{v}$ & Berhasil \\
\hline 5 & $125 \mathrm{~cm}$ & $\mathrm{v}$ & $\begin{array}{c}\text { Tidak } \\
\text { Berhasil }\end{array}$ \\
\hline 6 & $175 \mathrm{~cm}$ & & \\
\hline
\end{tabular}

\section{2.) Pengujian Sensor Ultrasonik HC-SR04}

Penginderaan sistem sampah penuh menggunakan sensor ultrasonic. Sensor Ultrasonik yang digunakan adalah HC-SR04 merupakan sensor yang dapat mengukur jarak objek dalam ukuran centi meter, pemasangan sensor ultrasonic diperlihatkan pada gambar berikut

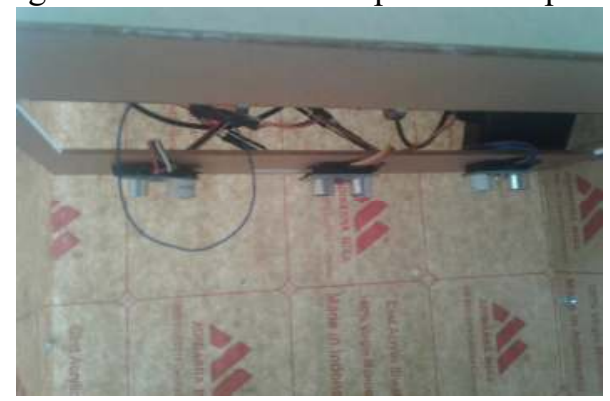

Gambar 4 Pemasangan sensor ultrasonic

GO INFOTECH: JURNAL ILMIAH STMIK AUB Vol. 24, No. 2, Desember 2018 : 124 - 133 
Pengujian dilakukan untuk melakukan monitoring level kepenuhan pada tempat penampungan dengan menggunakan mistar $40 \mathrm{~cm}$ sebagai pembandingnya. Untuk melakukan proses pembacaan ketinggian sampah yang telah dirancang ini menggunakan 3 buah sensor ultrasonic yang digunakan untuk mendeteksi ketinggian sampah logam, organik, dan anorganik. Hasil dari pengujian sensor ultrasonic sebagai sensor ketinggian sampah yang telah dilakukan, didapatkan nilai seperti pada tabel 2 .

Tabel 2 Pengujian Sensor Ultrasonik

\begin{tabular}{|c|c|c|c|}
\hline No & $\begin{array}{c}\text { Pengukuran dengan } \\
\text { menggunakan mistar }\end{array}$ & $\begin{array}{c}\text { Pengukuran dengan } \\
\text { sensor Ultrasonik }\end{array}$ & Selisih \\
\hline 1 & $1 \mathrm{~cm}$ & $1 \mathrm{~cm}$ & $0 \mathrm{~cm}$ \\
\hline 2 & $5 \mathrm{~cm}$ & $6 \mathrm{~cm}$ & $1 \mathrm{~cm}$ \\
\hline 3 & $10 \mathrm{~cm}$ & $9 \mathrm{~cm}$ & $1 \mathrm{~cm}$ \\
\hline 4 & $15 \mathrm{~cm}$ & $15 \mathrm{~cm}$ & $0 \mathrm{~cm}$ \\
\hline 5 & $20 \mathrm{~cm}$ & $22 \mathrm{~cm}$ & $2 \mathrm{~cm}$ \\
\hline 6 & $25 \mathrm{~cm}$ & $25 \mathrm{~cm}$ & $0 \mathrm{~cm}$ \\
\hline
\end{tabular}

Dari hasil pengujian sensor ultrasonik HC-Sr04 pada tabel 2 terlihat bahwa saat sensor mendeteksi objek dengan jarak cm, adapun hasil persentase Kesalahan Relatif diperoleh dari rumus $\mathrm{KR}=\frac{A R}{R} \times 100 \%$ Dimana $: \mathrm{KR}$ adalah kesalahan relatif, AR adalah nilai dari percobaan, $\mathrm{R}$ adalah nilai sesungguhnya. Hasil perbedaan Antara pembacaan sensor dengan pengukuran mistar ialah

$$
\begin{aligned}
& K R=\frac{A R}{R} \times 100 \% \\
& K R=\frac{1+6+9+15+22+25}{1+5+10+15+20+25} \times 100 \% \\
& K R=\frac{78}{76} \times 100 \% \\
& K R=1,026
\end{aligned}
$$

Jadi hasil presentase kesalahan rata-rata adalah 1,026\%

3.) Pengujian Sensor Proximity Kapasitif

Pengujian Sensor dilakukan untuk menguji fungsi sensing alat tersebut dapat mendeteksi. Pengujian sensor proximity kapasitif dilakukan dengan mendekatkan objek akan dikategorikan sebagai objek Anorganik. Gambar 5(a), (b), (c) pengujian proximity induktif.

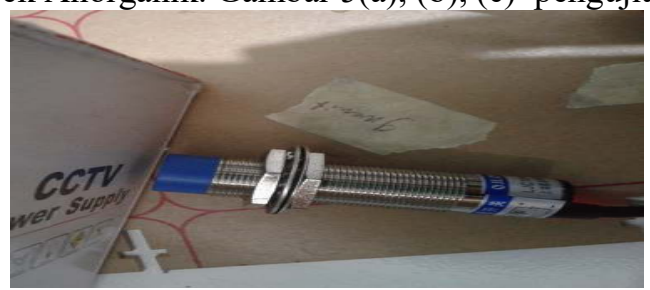

Gambar 5(a) Pemasangan sensor ultrasonic

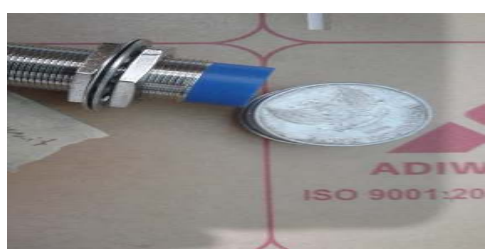

Gambar 5(b) Pemasangan sensor ultrasonic 


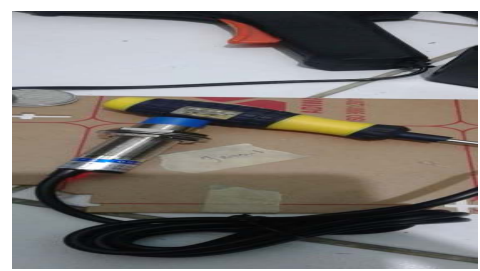

Gambar 5(c) Pemasangan sensor ultrasonic

Pengujian sensor kapasitif terlihat seperti gambar 5 (a), (b) dan (c) dengan kemampuan sensing berbagai jenis material. Pada gambar 5(a) pengujian dengan material berbahan kertas, gambar 5(b) pengujian dengan material berbahan logam, gambar 5(c) pengujian dengan material berbahan karet. Hasil pengujian bisa diketahui pada tabel 3 pengujian jenis sampah anorganik dilakukan dengan 10 kali percobaan serta pada gambar 6 adalah indikator sensor anorganik

Tabel 3 Hasil Pengujian Jenis Sampah anorganik

\begin{tabular}{|c|c|c|c|c|l|}
\hline \multirow{2}{*}{ No } & \multirow{2}{*}{ Jenis Sampah } & \multicolumn{3}{|c|}{ Sensor } & \multirow{2}{*}{ Ket. } \\
\cline { 3 - 5 } & & $\begin{array}{c}\text { Proximity } \\
\text { Inductive }\end{array}$ & $\begin{array}{c}\text { Proximity } \\
\text { Capacitive }\end{array}$ & Ultrasonik & \\
\hline 1 & Plastik static & - & v & v & Berhasil \\
\hline 2 & Plastik mie1 & - & v & v & Berhasil \\
\hline 3 & Plastik permen & - & - & v & Tidak \\
\hline 4 & Solasi & - & v & v & Berhasil \\
\hline 5 & Akrelic & - & v & v & Berhasil \\
\hline 6 & Aqua gelas & - & v & v & Berhasil \\
\hline 7 & Plastic sunlight & - & - & v & Tidak \\
\hline 8 & Bungkus obat & - & v & v & Berhasil \\
\hline 9 & Plastic mie2 & - & - & v & Tidak \\
\hline 10 & Botol & - & v & v & Berhasil \\
\hline
\end{tabular}

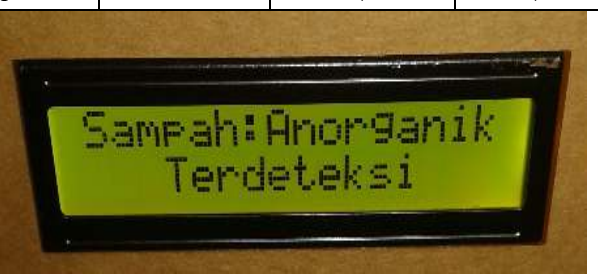

Gambar 6 Indikator Anorganik

Hasil pengujian bias dilihat pada tabel 4 pengujian jenis sampah organik dilakukan dengan 10 kali percobaan serta indikator organik pada gambar 7

Tabel 4 Hasil Pengujian Jenis Sampah Organik

\begin{tabular}{|c|c|c|c|c|c|}
\hline \multirow{2}{*}{ No } & \multirow{2}{*}{$\begin{array}{c}\text { Jenis } \\
\text { Sampah }\end{array}$} & \multicolumn{3}{|c|}{ Sensor } & \multirow{2}{*}{ Ket. } \\
\hline & & $\begin{array}{l}\text { Proximity } \\
\text { Inductive }\end{array}$ & $\begin{array}{l}\text { Proximity } \\
\text { Capacitive }\end{array}$ & Ultrasonik & \\
\hline 1 & Daun ke1 & - & - & $\mathrm{V}$ & Berhasil \\
\hline 2 & Tisu kel & - & - & $\mathrm{v}$ & Berhasil \\
\hline 3 & Daun ke2 & - & $\mathrm{v}$ & $\mathrm{v}$ & Tidak \\
\hline 4 & Kardus & - & - & $\mathrm{v}$ & Berhasil \\
\hline 5 & Kertas ke1 & - & - & $\mathrm{v}$ & Berhasil \\
\hline 6 & Kertas ke2 & - & - & $\mathrm{v}$ & Berhasil \\
\hline 7 & Daun & - & - & $\mathrm{v}$ & Berhasil \\
\hline 8 & Kardus ke2 & - & - & $\mathrm{v}$ & Berhasil \\
\hline 9 & Daun ke3 & - & $\mathrm{v}$ & $\mathrm{v}$ & Tidak \\
\hline 10 & Kertas ke3 & - & - & $\mathrm{v}$ & Berhasil \\
\hline
\end{tabular}




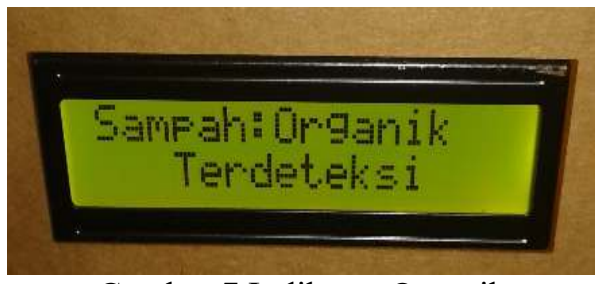

4.) Pengujian Sensor Proximity Induktif

Gambar 7 Indikator Organik

Pengujian sensor induktif terlihat seperti gambar 8(a) dan (b). Berbeda dengan sensor kapasitif yang dapat mendeteksi berbagai jenis material. Sensor Induktif ini hanya dapat membedakan logam dan non logam. LED indikator akan menyala dan mengirimkan data tegangan sebesar 4,37 volt, dan akan mati apabila tidak mendeteksi logam dan mengirimkan tegangan sebesar 0,5 volt. Sensor induktif ini memiliki range sensing yang sangat kecil. Berdasarkan pengujian, range sensing dari sensor adalah sekitar $4 \mathrm{~mm}$. pengujian bias dilihat pada gambar 8

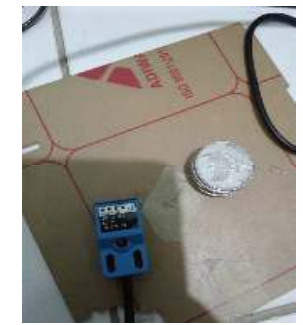

(a)

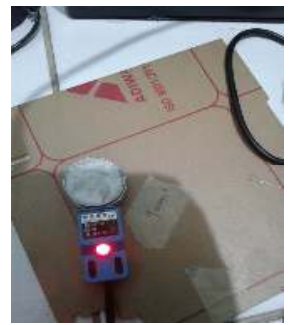

(b)

Gambar 8(a) Tampilan Sensor Induktif yang tidak mendeteksi logam, (b) Tampilan Sensor Induktif yang mendeteksi logam

Hasil pengujian bisa diketahui pada tabel 5 pengujian jenis sampah Metal/Logam dilakukan dengan 10 kali percobaan serta pada LCD menampilkan indikator sampah metal

Tabel 5 Hasil Pengujian Jenis Sampah Metal

\begin{tabular}{|c|l|l|l|l|l|}
\hline \multirow{2}{*}{ No } & \multirow{2}{*}{$\begin{array}{c}\text { Jenis } \\
\text { Sampah }\end{array}$} & \multicolumn{3}{|c|}{ Sensor } & \multirow{2}{*}{ Ket. } \\
\cline { 3 - 6 } & & $\begin{array}{c}\text { Proximity } \\
\text { Inductive }\end{array}$ & $\begin{array}{l}\text { Proximity } \\
\text { Capacitive }\end{array}$ & Ultrasonik & \\
\hline 1 & Mur & v & - & v & Berhasil \\
\hline 2 & Baut & v & - & v & Berhasil \\
\hline 3 & Paku & v & - & v & Berhasil \\
\hline 4 & Pisau & v & v & v & Tidak \\
\hline 5 & Uang logam & v & - & v & Berhasil \\
\hline 6 & Sendok & v & - & v & Berhasil \\
\hline 7 & Garpu & v & - & v & Berhasil \\
\hline 8 & Pinset & v & - & v & Berhasil \\
\hline 9 & Obeng & v & - & v & Berhasil \\
\hline 10 & Paku & v & - & v & Berhasil \\
\hline
\end{tabular}

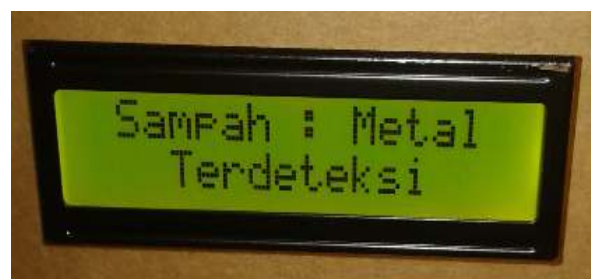

5.) Pengujian Keseluruhan

Gambar 9 Indikator Metal 
Pengujian hasil keseluruhan hanya dilakukan jika pengujian masing-masing komponen telah dilakukan dengan benar. Setelah itu menggabungkan seluruh komponen dan program agar masing-masing komponen mampu menjalankan fungsinya sehingga menjadi sebuah alat yang sesuai dengan perencanaan. Alat akan dilakukan pengujian secara keseluruhan agar mendapatkan data yang sesuai.

3.2 Pembahasan

Alat pemilah sampah otomatis yang telah selesai dalam perancangan dan sudah diimplementasikan dalam perakitan komponen serta telah dilakukan pengujian dan diperlihatkan hasil pengujian maka dari itu cara penggunaan alat pemilah sampah otomatis sebagai berikut:

1.) Nyalakan Catu Daya.

2.) Masukan sampah kedalam kotak sampah

3.) Tunggu proses sensing sampah.

4.) Setelah sensing sampah selesai LCD akan menampilkan informasi jenis sampah yang terdeteksi.

5.) Jika sampah penuh, indikator led dan buzzer akan menyala serta LCD akan menampilkan informasi keadaan sampah.

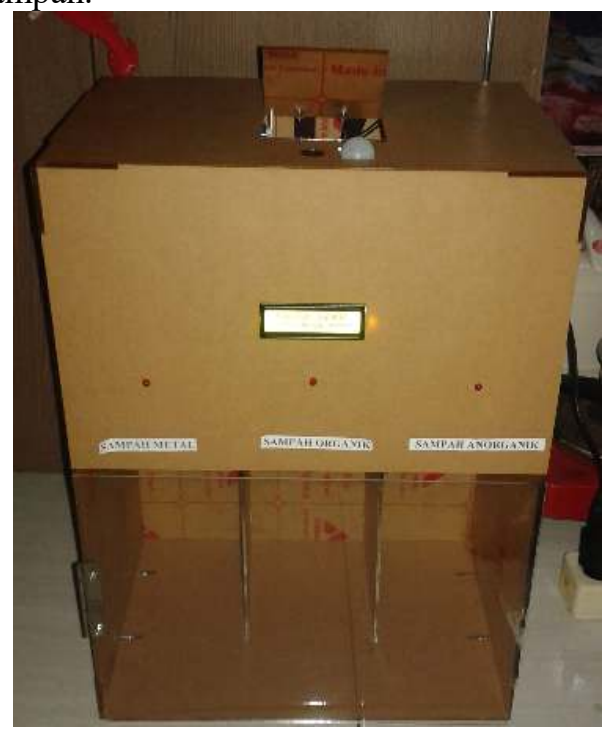

Gambar 10 Prototype Alat Pemilah Sampah Saat Membuka Pintu

\section{KESIMPULAN}

Kesimpulan dari hasil pengujian dan penelitian Rancang Bangun Alat Pemilah Sampah Otomatis berbasis Arduino Mega Atmega2560 yang telah dilakukan, dapat disimpulkan bahwa Alat Pemilah Sampah Otomatis telah berhasil dirancang dan dibangun menggunakan Arduino Mega Atmega 2560 sebagai pusat kendali dengan Sensor Proximity Inductive sebagai Alat pemilah sampah Logam/Metal, dan Sensor Proximity Capacitive sebagai Alat pemilah sampah Anorganik, serta Sampah yang tidak terdeteksi oleh sensor masuk ke bak penampung sampah Organik.

\section{DAFTAR PUSTAKA}

[1] Andrianto, H. 2013. Pemrograman Mikrokontroler AVR ATMegal6 Menggunakan Bahasa C. Bandung : Informatika Bandung.

GO INFOTECH: JURNAL ILMIAH STMIK AUB Vol. 24, No. 2, Desember 2018 : 124 - 133 
[2] Bimantara, Christian. 2017. Rancang Bangun Lengan Robot Berjalan (Mobile Robotic Arm) Berbasis Arduino Uno R3 Di Kendalikan Dengan Ps2xwireless. Surakarta : STMIK AUB Surakarta.

[3] Bolton ,W. 2004. Programmable Logic Controller (PLC) Sebuah Pengantar. Edisi Ketiga. Penerbit Erlangga.

[4] Djuandi Feri, 2011. Artikel Pengenalan Arduino. http://toboku.com/docs/ArduinoPengenalan.pdf. diakses 25 Mei 2018

[5] Febri Megantara, 2013. Pembuka dan Penutup Bak Sampah Otomatis. Yogyakarta : Universitas Negeri Yogyakarta.

[6] Hin, K. 2007. Pemrograman Mikrokontroler PIC 16F84A. https://idschool.net/umum/kode-warna-resistor-dan-cara-hitung/. Diakses 25 mei 2018

[7] Indrajani, 2011. Pengertian dan Prinsip Kerja Lcd. http://www.robotikauns.net/2014/01/pengetian-dan-prinsip-kerja-lcd/. diakses 25 Mei 2018

[8] Jogiyanto, HM. 2005. Analisis \& Desain Sistem Informasi Pendekatan Terstruktur Teori dan Praktek Aplikasi Bisnis. Yogyakarta : Andi Offset

[9] M. T. M. Allen Reicks, 2004. Bulk Material Handling by Conveyor Belt 5. Small Medium Enterprises. https://klinikrobot.com/mobile-articles/126-7-hal-yang-perludiketahui-tentang-motor-dc-gearbox.html. diakses 07 Juni 2018

[10] Mahardika, Tegar. 2010. Sensor Ultrasonik HC SR-04. Semarang : Universitas Negeri Semarang.

[11] Nugroho, 2013. Membuat Pupuk Kompos. Jakarta : Publishing Informatika.

[12] Nurcahyono, 2012. Tempat Sampah Pintar Menggunakan Mikrokontroler ATMega8535. Yogyakarta : Universitas Negeri Yogyakarta.

[13] Pressman, Roger, S. 2001, Software Engineering: A practitioner's Approach, Fifth Ed.New York, Mc.Graw-Hill Book Company.

[14] Purnama sono, 2014. Perancangan Tempat Sampah Otomatis Tanpa Sentuh Berbasis Mikrokontroler Arduino. Yogyakarta : Fakultas Teknik Universitas Mercu Buana.

[15] Raharjo, 2005. Mengenal Komponen Elektronika. Jakarta : Departemen Pendidikan Nasional.

[16] Rizki Antoni, M. Sarwoko, Ir., M.Sc, Unang Sunarya, ST.,MT, 2015. Analisis dan implementasi sistem sensor pada tempat sampah otomatis dengan metode fuzzy berbasis mikrokontroller.

[17] Rustamadji, 2008. Cara Mengakses Module Sensor Line Proximity Menggunakan Arduino.https://www.nyebarilmu.com/cara-mengakses-module-sensor-line-proximitymenggunakan-arduino/. diakses 25 mei 2018

[18] Santoso, 2015. Panduan Praktis Arduino Untuk Pemula. http://www.scribd.com/document/239615817/Arduino. diakses 25 mei 2018

[19] Sugiyono, 2013. Metodelogi Penelitian Kuantitatif, Kualitatif Dan R\&D. Bandung : Alfabeta.

[20] Suharjo, 2014. Tempat Sampah Otomatis Berbasis Mikrokontroler Atmega16. Surakarta : STMIK AUB Surakarta. 